\title{
Value Creation by Dynamic Pricing through Digitization and Industry-Wide Perspective
}

\author{
Wolfgang Neussner ${ }^{1}$, Daniel Ebner ${ }^{1} \&$ Maximilian Lackner ${ }^{1}$ \\ ${ }^{1}$ University of Applied Sciences Technikum Wien, Hoechstaedtplatz 6, 1200 Wien, Austria \\ Correspondence: Wolfgang Neussner, University of Applied Sciences Technikum Wien, Hoechstaedtplatz 6, \\ 1200 Wien, Austria.
}

Received: November 16, 2021

Accepted: December 12, $2021 \quad$ Online Published: December 30, 2021

doi:10.5539/ijef.v14n1p115

URL: https://doi.org/10.5539/ijef.v14n1p115

\begin{abstract}
Dynamic Pricing (DP), also known as surge pricing or dynamic price management, is the adjustment of prices for goods and services depending on the current market situation. Its purpose is to maximize profit, and the practice is getting more and more common. Dynamic pricing was first spotted in online retail; Also in offline retail, it can be found, e.g. as electronic price tags, as well as in on-demand services in mobility and smart meters in the energy industry. Dynamic pricing offers opportunities for vendors. The goal of this paper is to examine the current status and the new opportunities and risks of Dynamic Pricing in retail, mobility and the energy sector, made possible by digitization. This is done on the one side with expert interviews and on the other with an online research. 5 experts were interviewed and 238 respondents answered a questionnaire. 12 hypotheses were formulated, out of which 9 were confirmed, 1 was completely rejected and 2 were partially rejected. The unexpected results were: (1) Electronic price labels in stationary retail trade do not worry consumers with regard to momentary price changes. (2) Consumers do not prefer dynamic pricing models in car sharing. (3) Consumers can benefit from dynamic pricing models in the case of the aviation industry.
\end{abstract}

The aim of this work to provide readers with insights as on how to utilize DP in their respective industries.

Keywords: Dynamic Pricing (DP), surge pricing, price management, price models, retail, mobility, energy supply, digitization

\section{Introduction}

\subsection{Pricing and Dynamic Pricing}

Every single good or service comes with a price, and pricing is one of the most important tasks of management. The price is one of the decisive factors for whether a deal happens or not, and to whose advantage that transaction goes. Interestingly, pricing is often neglected. Prices can be prescribed, e.g. through resale price maintenance (RPM) (Guan-Ru \& Miao-Ling, 2011), or, generally, be formed by the market forces between supply and demand. Digitalization inevitably leads to the generation of more data, which can serve as the basis for new pricing strategies. By means of price optimization, the greatest leverage on the profitability of a company can be generated. Dynamic pricing (DP) allows companies to adapt prices to current conditions, even on the individual customer level. Dynamic pricing is already common in the mobility industry and in online retailing, but now energy suppliers are also offering their customers dynamic prices. In stationary retail, the harbingers of dynamic pricing can already be seen: retailers are increasingly using electronic price tags to enable real-time price changes. Influencing factors are usually time of day, day of the week, stock level or demand. A study conducted by the Vienna Chamber of Labour in 2017, surveyed for the tourism and travel sector, found that on online booking portals, prices for hotels, as well as for airline tickets, sometimes change within five minutes (Horvath, 2019).

For pricing, there are already extensively researched management methods in science to calculate the pricing models industry-specifically (Schuppar, B. R., Schuppar, B., \& Homburg, 2006). For dynamic pricing, the price differentiation or price discrimination methods are of particular importance.

Price management is the analysis, planning, setting, enforcement and monitoring of prices in a business context, distinguishing between pricing decisions at the level of pricing strategy and pricing systems and price-related activities involving pricing and price enforcement. 
Information also plays an important role in price management, and a distinction is made between four main types of information (Schuppar, B. R., Schuppar, B., \& Homburg, 2006). These include price-related cost information - if the price is determined on the basis of information on the manufacturing costs for the goods or on the costs of the services, this is also referred to as "cost-plus" pricing. Here a target margin is added to the costs of the goods or services, the price-related competitive information - prices are formed on the basis of competitive information, so goods must be found on the market that are comparable to the own one (substitute goods). The net sales prices are compared with these and a price decision is made on this basis, the price-related customer information - the price decision is made on the basis of information on the customers' willingness to pay and price elasticity. If the quantity demanded of a product changes strongly in response to changes in its price, it is called "elastic". Examples are luxury products. Examples for inelastic products, where price changes do not affect demand, are e.g. tobacco and prescription drugs.

The aim is to identify the customer's willingness to pay at which he is not yet ready to change the supplier (Schuppar, B. R., Schuppar, B., \& Homburg, 2006), as well as the manufacturer-oriented price calculation. The vertical price fixing in the trade (except for books) has already been abolished, still "recommended retail prices" of the manufacturers play a strong role in the retail trade. Manufacturers can cultivate through products a brand image, which is passed on to consumers through retailers and thereby also characterizes the quality of the retailer Hartmann (2006).

In many markets, especially in the high-tech segment, there is currently a trend towards the rapid introduction of new products. Product life cycles have become increasingly short, and customers demand for, or are at least offered, new, i.e. updated or improved products within short time frames. Pricing is a very important and demanding task, both in terms of the financial success of a product and subsequently for the company. Pricing can also be decisive for the quality perception of customers towards new products. Overpricing can hinder the sales launch and market diffusion of products, signaling heavy discounting as a sign of miscalculation on the part of the firm (Spann, Fischer, \& Tellis, 2015). Therefore, marketing literature usually mentions two basic strategies, market skimming and penetration pricing strategy.

Price discrimination (or price differentiation), refers to the differentiation of prices for different customer segments, according to spatial, temporal, quantitative or qualitative criteria. The differentiation on the basis of customer segments, which is characterized by certain social criteria such as students, pensioners or members of certain associations, can be recognized by any discounts on the services offered, such as a canteen, in which only people from the environment of a university can consume the goods Helmedag (2001).

Time-based price differentiation is used if there is no unequal treatment with regard to the spatial, service and quantity-based components. In this model, differentiation is primarily made according to times of day, days of the week or season; this allows peaks in demand, as well as missing periods of demand, to be compensated for. In the case of energy providers, electricity is cheaper at night, while tourist activities and air fares are more expensive in peak seasons. Other obvious examples are prices of hotel beds in times of large trade fairs or winter clothes in late spring. The strategy of a company is designed to guarantee a long-term and profitable business. The development of strategy is based on the goals that a company is trying to achieve, from which in turn direct goals for price management are derived. Many companies strive to achieve profitability goals (profit, return on sales, return on investment, shareholder value) and volume and growth goals (sales volume, market share, sales or sales increase) (Simon \& Fassnacht, 2019). These goals can be realized more easily through dynamic pricing, because it tries to charge the highest possible price for a product from each customer segment. Due to the increasing integration of digitalization in the form of electronic commerce, the possibilities of offering consumers a personalized price are growing (Olbrich \& Battenfeld, 2014).

A study by the French data protection authority also identified personal price differentiations in the mobility sector, for example for flights and rail travel. Prices differed not only on the basis of ticket availability or the time of demand, but also on the basis of browsing history (Taillard \& Trochet-Macé, 2014).

In this chapter, the sectors relevant for this paper (trade, mobility and energy supply) are examined in more detail. The following are dealt with in detail:

The selection of industries was based on the current innovations made possible by digitalization in terms of dynamic pricing. Online retail is increasingly associated with personal pricing, while electronic shelf labeling is being used more and more frequently in stationary retail (Heinemann, Gehrckens, \& Täuber, 2019). In the field of mobility, a trend towards the sharing economy can be seen, especially in urban areas, whereby mobility becomes a service. These new concepts make it easier to apply dynamic pricing models (Vetter, 2019). Smart meters allow energy providers to measure energy consumption at smaller intervals, paving the way for new 
pricing models. In the tourism industry, the concept of dynamic pricing is already widely applied, so this industry is already well researched (Horvath, 2019).

Dynamic pricing models are located at the interface between operations research, marketing, microeconomics and e-commerce. Data, some of which can be analyzed in real time, is becoming increasingly important for current forms of dynamic pricing (Goensch, Klein, \& Steinhardt, 2009). For this, modern data management is needed (Bonacchi \& Perego, 2019). If a fixed supply capacity is assumed, dynamic pricing results in a maximization of the contribution margin, which can be explained on the basis of two theses: By differentiating prices over time, the supplier can exploit any changes in the customers' willingness to pay over time. In periods of inelastic demand, the company tends to set higher product prices than in periods of high elasticity. Dynamic pricing allows the firm to respond to random fluctuations in demand and use them to generate revenue. If unexpectedly high demand occurs when supply capacity is tight, prices tend to be increased to serve consumers with low price sensitivity, thereby generating higher contribution margins. If unexpected demand shortfalls occur, prices tend to be lowered to take advantage of supply capacity (Oxera, 2018).

By moving from product to channel and customer profitability analysis, sales and marketing departments are expected to find the best types of customers and acquire and retain them. For this measurement, there are three key marketing-related indicators (Bonacchi \& Perego, 2019), which should help to implement a customer-centric strategy. These include customer profitability, customer lifetime value, and customer equity. Customer Profitability describes the difference between the revenue from the customer relationship and the associated costs in a certain period of time. This key figure provides clarity for which customers, how much resources should be spent in order to maintain a long-term profitable relationship. With Customer Lifetime Value, a value can be assigned to individual customers or customer segments, which is made up of future cash flows. Customer equity describes the value of the current customer base added to the potential customers that would be attractive to the company, i.e. an aggregated result of the customer lifetime value. In this context, customer equity represents an intangible asset of the company, which is influenced by management methods and can lead to the reduction, retention or increase of the customer base (Bonacchi \& Perego, 2019).

Pricing algorithms can in many cases help to make the market more attractive for consumers, as the application of technology helps them to obtain increased price transparency. On a policy level, there are still some challenges to overcome in terms of legislation in the areas of regulatory and competition law. When algorithms make autonomous pricing decisions, this can lead to a perceived unfairness among consumers, which can subsequently lead to punitive or avoidant reactions. It is obvious that the information consumers provide to companies is used for pricing. However, it is questionable how such pricing models will be accepted by society as a whole and how the interaction between companies, consumers and the bodies representing the government will work out in the future (Oxera, 2018).

\subsection{Legal Framework}

Companies are free to set their prices as it is up to the consumers whether they want to enter into a contract with a company or not. Dynamic or personal pricing is not explicitly regulated in Austrian legislation. Therefore, companies are allowed to define prices according to their own criteria and to apply price differentiation. From a legal point of view, however, it becomes problematic if different prices are based on discriminatory characteristics or if the necessary transparency with regard to price differentiations is lacking Horvath, L. (2019). These price changes over time, or other group-specific characteristics are quite legally justifiable, but for consumers disadvantages can arise from the lack of transparency with regard to the price composition of products or services. A legally more problematic situation is represented by personal pricing, which is currently mainly used in online retailing. In the United States of America, it has already been possible to prove personal price differentiation, but not which characteristics of the consumers were decisive for this (Hannak et al., 2014).

\section{Experimental}

\subsection{Hypotheses}

The aim of this survey is to conduct a qualitative data collection by means of expert interviews. The experts were selected according to the following criteria: The expert is very familiar with the pricing of the company, demonstrates industry-relevant know-how and follows the current developments of digitalization and the associated opportunities that arise from it. In total, 12 hypotheses H1-H12 were formulated.

H1: Dynamic pricing models give consumers the perception of being able to purchase products at lower prices.

H2: Consumers perceive the inclusion of personal data in the pricing process as unfair.

H3: Transparency of prices in terms of costs and pricing criteria is very important to consumers. 


\section{$\underline{\text { Trade }}$}

For stationary trade, the application and effect of electronic price tags is of particular relevance. In addition, it is of interest for this work to determine the amounts above which steering effects can be achieved through dynamic prices. With regard to e-commerce, the importance of transparent prices will be investigated.

H4: Electronic price labels in stationary retail trade worry consumers with regard to momentary price changes.

H5: Steering effects through dynamic price models show effect in stationary food retailing. Consumers satisfy their demand during periods of lower prices.

H6: Consumers would like to see greater transparency of prices with regard to costs and pricing criteria in e-commerce.

\section{Mobility}

The hypothesis formation of the mobility industry starts with two passenger transport methods, whereby dynamic prices are already well established in the aviation industry. In car sharing, static pricing models are currently used. The relevance of the awareness of cost and price composition, on the part of the consumers, is also to be explained with the help of the survey. Finally, areas of application in which consumers may consider dynamic pricing models to be advantageous will be discussed.

H7: Consumers prefer dynamic pricing models a) in the airline industry and b) in car sharing.

H8: Consumers would like to see greater transparency of prices with regard to costs and pricing criteria in the mobility sector.

H9: Consumers can benefit from dynamic pricing models in the case of
a) Parking garages
b) Public charging points for electric cars
c) Car sharing
d) Driving service provider
e) Aviation industry
f) Public transport

In other words, they can rrecognize personal price advantages.

\section{Energy supply}

Since new technologies make the operation of household appliances controllable in terms of time, it is investigated whether consumers would be willing to use them in order to achieve possible price advantages. The expert interviews also revealed that electricity is not perceived as costly enough in private households and is rather perceived as a commodity. Based on this thesis, it is tested whether consumers would be willing to expose themselves to the risk of the wholesale energy market.

H10: Consumers would be willing to adapt their energy consumption to real-time market changes with the help of smart devices in order to reduce energy costs.

H11: Consumer demand for energy is very inelastic, as electricity is perceived as a commodity.

H12: Consumers do not want to be at the mercy of the market risk of the energy wholesale market.

\subsection{Questionnaire Design}

The questionnaire was created with the help of the website www.umfrageonline.com. At the beginning, the respondents were informed about dynamic pricing models and the general conditions of the survey were explained. After introducing the respondents to the topic, there follows a section discussing demographic characteristics. On the third page of the online questionnaire, respondents are asked basic questions about dynamic pricing

The evaluation of the collected data material is carried out with the help of the statistical software SPSS. The results are divided into four categories, a section on dynamic pricing, trade, mobility and energy supply. The analysis will also examine the sample for any differences in demographic factors.

\section{Results - Qualitative Research Findings}

A total of five guided interviews were conducted to collect the data. This chapter explains how the practical data collection took place and how it was analysed. 
Table 1. The experts

\begin{tabular}{|c|c|c|}
\hline Designation & Position & Duration (hh:mm:ss) \\
\hline & Partner & \\
\hline \multirow[t]{2}{*}{ IP1 } & Austrian strategy consulting firm & 00:18:03 \\
\hline & Head of PR and Communication & \\
\hline \multirow[t]{2}{*}{ IP2 } & Company spokeswoman & 00:19:03 \\
\hline & Austrian retail manager, senior researcher & \\
\hline \multirow[t]{2}{*}{ IP3 } & Austrian telecommunications institute & 01:08:26 \\
\hline & research engineer & \\
\hline \multirow[t]{2}{*}{ IP4 } & Austrian research institute & 01:08:26 \\
\hline & Team leader corporate development & \\
\hline IP5 & Vienna Energy corporation & $00: 24: 55$ \\
\hline
\end{tabular}

The information in the subsections 3.1 to 3.3 is referenced to the five experts by the addition of (IPX/Z:Y), where $\mathrm{IP}=$ expert (interview partner), $\mathrm{X}=1-5$, and $\mathrm{Y}$ is the line of text in the transcript $(\mathrm{Z})$.

\subsection{Trade}

With regard to stationary trade, the experts disagreed. On the one hand, it was predicted that electronic price tags would establish more dynamic prices in relation to the time of day and customer groups in the medium term. (IP1/Z:70) On the other hand, this was denied on the grounds that the trust of consumers in local suppliers would be too badly affected. (IP2/Z:27) In the Netherlands such a concept has already been implemented with the pretext of having to throw away less food. (IP4/Z:127) Another aspect that speaks for the wider use of dynamic pricing models is that higher margins can be generated. (IP2/Z:63) In online retailing dynamic prices are much easier to implement, it is also easier to generate data and determine prices based on this. (IP2/Z:78) However, it will be difficult for online food retailing to gain market share in Austria due to the high density of local suppliers, whereas this is quite conceivable in countries with lower density. (IP2/Z:118) In e-commerce for non-perishable consumer goods, however, dynamic pricing models, also in the form of personal prices, will increasingly prevail. (IP4/Z:136).

\subsection{Mobility}

Dynamic pricing models are already used in car parks to achieve a better distribution of available capacity. (IP1/Z:57) In order to achieve a shift of mobility demanders from private cars to public transport through dynamic pricing, price is too small a factor to achieve effects. (IP1/Z:119) In the Netherlands a dynamic pricing model for public transport is already used, but with moderate success, because customers find the price fluctuations of up to five euros too unattractive. (IP3/Z:218) Here, too, there is a lack of clear price transparency. According to one expert, it is much more likely that charging stations for electric cars will apply dynamic pricing models similar to those used at fuel filling stations. (IP1/Z:108) Another expert denied this and spoke of concepts such as selling a full charge in a certain time period (about $8 \mathrm{~h}$ ) as a service. This is easier to control for the energy industry due to the permanently changing grid load. (IP5/Z:83/Z:92) Even with car sharing models, which now work with machine learning algorithms, consumers lack the necessary transparency and certainty with regard to their costs. (IP3/Z:221) For the future, the background, which criteria lead to a change in price, must be clearly defined in order to guarantee consumers a better insight into pricing (IP3/Z:224).

\subsection{Energy Supply}

The wholesale energy market currently serves as a pricing platform for energy suppliers, with the price of electricity being determined by supply and demand. (IP4/Z:245) If price peaks occur, the increased price is passed on to consumers in a flattened form. (IP5/Z:39) This is a static model, which is far from real-time pricing. (IP5/Z:18) Only larger fluctuations in prices or higher electricity consumption would make dynamic pricing more attractive. (IP5/Z:47/Z:118) The involvement of consumers is too low for the product electricity, because it is perceived as a commodity. (IP1/Z:99) Direct market risk may also be a deterrent for end-users as they would be at the mercy of any price spikes. (IP5/Z:126) Since dynamic prices would benefit consumers with PV systems and higher energy consumption in particular, i.e. a more affluent clientele, static price models are more fair for society as a whole. (IP5/Z:120)

In addition to the low energy prices, the current pricing model of the network operators poses a major challenge for the application of dynamic pricing. They charge a basic fee for which the network supply is provided in return; it would be necessary to convert this static pricing model into a dynamic one in order to be able to 
cushion performance peaks through steering effects. (IP5/Z:70) Technological advances are also needed in relation to smart meters, as at present electricity consumption can be measured every quarter of an hour, but the data is not available to the supplier until the following day. (IP5/Z:58) In general, business models in the energy industry need to be more customer-centric. (IP5/Z:138) Smart appliances can also contribute to the further integration of dynamic pricing, for example, large energy consumers such as washing machines or dryers can be activated using time controls to take advantage of low market prices. (IP3/Z:108) There is also an increasing trend towards systems such as heat pumps, electric cars or PV systems, which will create a new awareness of electricity as a product among customers. (IP5/Z:149) The resulting cost awareness will make it easier to establish new pricing models, and tariffs could be individualised online according to demand, i.e. adapted to household-specific energy consumption. (IP5/Z:134)

\section{Quantitative Research Results}

A total of 238 participants were engaged in the period from 28/04/2020 to 01/05/2020. These were generated through social media, personal contacts and forums. No particular stratification apart from geography (German-speaking countries only) was done; The participants belonged to all genders and age groups, as detailed below. The sampling is considered to be representative.

The analysis of the collected data material is carried out using the statistical software SPSS from IBM. Out of the 238 respondents, 215 respondents completed the questionnaire in full. The age of the participants ranged from 17-68 years, with a mean of 29.50 years for the sample collected. The participants are resident in Germany, Austria and Switzerland, whereby it should be noted that 28 respondents did not wish to disclose their current place of residence and of the remaining sample of 187 persons, 32.1 percent are resident in Vienna. The total sample consists of 42.8 percent male and 57.2 percent female participants. Regarding the educational qualifications of the respondents, it can be mentioned that about $20 \%$ have a Bachelor's degree and about $16 \%$ have a Master's degree.

The analysis of the block of questions relating to hypothesis 1 shows that the largest proportion (36.7 percent) of the participants surveyed compare prices online and, if prices are perceived to be too high, delay the purchase decision in order to wait for cheaper prices. No significant differences were found with regard to gender. However, it is evident that the majority of respondents tend to compare prices online frequently and only 7.9 percent do not inquire about the prices of products at all. The sample was divided into three age groups with the help of SPSS, the under 27 year olds were given the characteristic 1, the 27-50 year olds were given the characteristic 2 and the participants over 50 were given the characteristic 3 . It can be seen that the younger participant groups (1 and 2) in particular compare prices online more often than average.

Table 2. Cross-tabulation of prices by age group

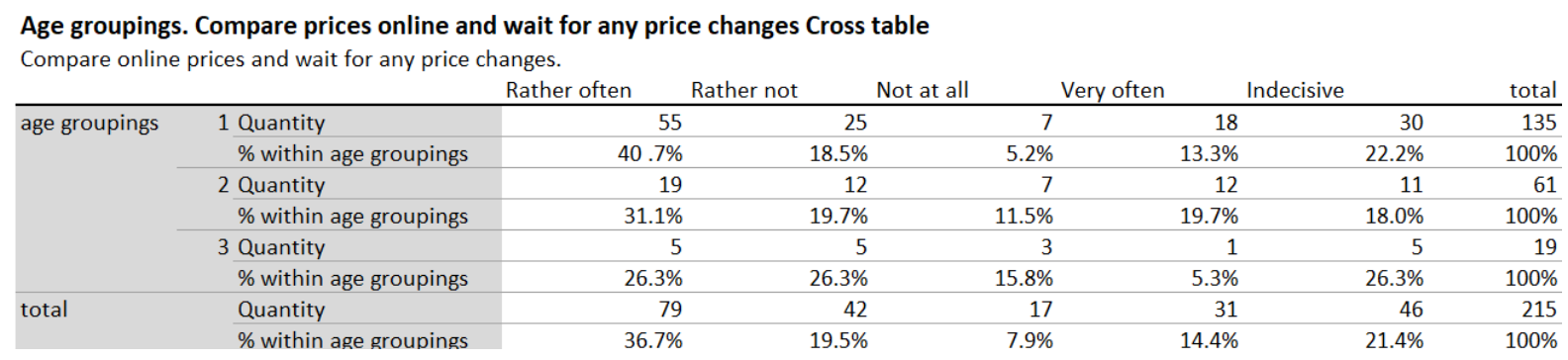

Question 2, whether consumers feel that they get better prices, shows that more than half of the participants $(53.49 \%)$ think that they get a monetary advantage by following dynamic prices.

The cross table, with the breakdown by age group, shows that especially the older group of participants shows a tendency towards the middle. 42 percent are of the opinion that they benefit from dynamic prices rather frequently, and 21 percent each are undecided or think that they cannot achieve any advantages through this, the rest do not compare prices online. In the younger groups ( 1 and 2), a total of 63.9 percent said they thought they could shop more cheaply thanks to dynamic prices. 
Table 3. Cross-tabulation of personal feelings by age group

Age groups - How often do they think they have been able to buy at a lower price? Cross table

\begin{tabular}{|c|c|c|c|c|c|c|c|c|}
\hline & & Rather often & Rather not & Not at all & not comparing & Very often & Indecisive & total \\
\hline \multirow[t]{6}{*}{ age groupings } & 1 Quantity & 59 & 10 & 0 & 14 & 16 & 36 & 135 \\
\hline & $\%$ within age groupings & $43.7 \%$ & $7.4 \%$ & $0.0 \%$ & $10.4 \%$ & $11.9 \%$ & $26.7 \%$ & $100.0 \%$ \\
\hline & 2 Quantity & 23 & 7 & 1 & 9 & 9 & 12 & 61 \\
\hline & $\%$ within age groupings & $37.7 \%$ & $11.5 \%$ & $1.6 \%$ & $14.8 \%$ & $14.8 \%$ & $19.7 \%$ & $100.0 \%$ \\
\hline & 3 Quantity & 8 & 4 & 0 & 3 & 0 & 4 & 19 \\
\hline & $\%$ within age groupings & $42.1 \%$ & $21.1 \%$ & $0.0 \%$ & $15.8 \%$ & $0.0 \%$ & $21.1 \%$ & $100.0 \%$ \\
\hline \multirow[t]{2}{*}{ total } & Quantity & 90 & 21 & 1 & 26 & 25 & 52 & 215 \\
\hline & $\%$ within age groupings & $41.9 \%$ & $9.8 \%$ & $0.5 \%$ & $12.1 \%$ & $11.6 \%$ & $24.2 \%$ & $100.0 \%$ \\
\hline
\end{tabular}

With regard to the question concerning the perception of fairness through the inclusion of personal information in the price determination, a similar distribution was found for all age groups, and there were also no significant gender-specific differences. If one's own price is lower than that of an acquaintance at the same time and place, the feeling of unfairness outweighs the personal price advantage for the majority of respondents. More than $80 \%$ consider this to be rather unfair or very unfair. Also in the counter-question, if the own price is higher than that of the acquaintance or the acquaintances, it could be determined that there is a strong feeling of unfairness for more than $88 \%$ of the participants.

The question in block three, was focused on the cost and pricing criteria and how much interest the respondents have in it while making purchase decision of the products. The following bar chart shows that 59.07 percent of the participants are very or rather interested in the formation of prices.

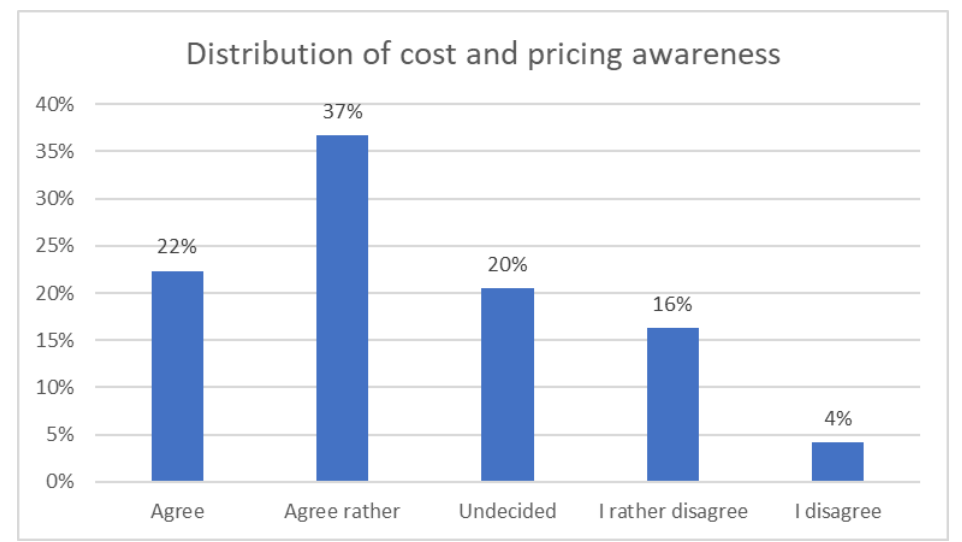

Figure 1. Distribution of cost and pricing awareness

\subsection{Trade}

The first question in the retail-specific section of the questionnaire deals with electronic price tags. As discussed earlier in this paper, these can have prices changed in real time, which would allow for price differentiation based on time of day in brick-and-mortar retail. No significant differences were seen through all age groups, neighborhoods, and genders. The distribution shows that 42.79 percent of the respondents are rather worried or very worried, 18.6 percent are undecided and 38.61 percent are rather not worried or not worried at all about the use of electronic shelf labeling.

To answer the hypothesis regarding the steering effects of price differentiation in food retailing, two questions were created. The first deals with a small thought experiment. Here, participants are asked at what price differentials they would buy their lunch at 08:00 instead of 12:00. The result of the whole sample $(n=215)$ is illustrated in the following figure. It can be seen that already about ten percent of the respondents would be willing to adjust their shopping behaviour at a price difference of ten percent ( 0.50 euros). From a difference of 1.5 euros ( 30 percent), more than half of the participants would be willing to get their lunch in the morning

Looking at the cross-table with the breakdown by age groups, it can be seen that younger consumers in particular would already change their purchasing behaviour at lower price differences. For the older participants, a higher monetary advantage must be given in order to achieve any steering effects. 
Table 4. Cross-tabulation of price sensitivity by age group

\begin{tabular}{|c|c|c|c|c|c|c|c|}
\hline & & $\begin{array}{l}0,50 € \\
\text { (new price } 4,50 € \text { ) }\end{array}$ & $\begin{array}{l}1,00 € \\
\text { (new price } 4,00 € \text { ) }\end{array}$ & $\begin{array}{l}1,50 € \\
\text { (new price } 3,50 € \text { ) }\end{array}$ & $\begin{array}{l}2,00 € \\
\text { (new price } 3,00 € \text { ) }\end{array}$ & $\begin{array}{l}2,50 € \\
\text { (new price } 2,50 € \text { ) }\end{array}$ & total \\
\hline \multirow[t]{6}{*}{ age groupings } & 1 Quantity & 18 & 23 & 35 & 27 & 32 & 135 \\
\hline & $\%$ within age groupings & $13.3 \%$ & $17.0 \%$ & $25.9 \%$ & $20.0 \%$ & $23.7 \%$ & $100.0 \%$ \\
\hline & 2 Quantity & 3 & 13 & 15 & 9 & 21 & 61 \\
\hline & $\%$ within age groupings & $4.9 \%$ & $21.3 \%$ & $24.6 \%$ & $14.8 \%$ & $34.4 \%$ & $100.0 \%$ \\
\hline & 3 Quantity & 0 & 2 & 6 & 3 & 8 & 19 \\
\hline & $\%$ within age groupings & $0.0 \%$ & $10.5 \%$ & $31.6 \%$ & $15.8 \%$ & $42.1 \%$ & $100.0 \%$ \\
\hline \multirow[t]{2}{*}{ total } & Quantity & 21 & 38 & 56 & 39 & 61 & 215 \\
\hline & $\%$ within age groupings & $9.8 \%$ & $17.7 \%$ & $26.0 \%$ & $18.1 \%$ & $28.4 \%$ & $100.0 \%$ \\
\hline
\end{tabular}

In response to the direct question of whether the participant would adjust his or her shopping behaviour on the basis of price advantages, the overwhelming majority of 77.68 percent tended to agree or agreed. With regard to e-commerce, there was a similar distribution of interest in costs and pricing criteria as in the section on dynamic pricing.

\subsection{Mobility}

The questions on mobility initially dealt with attitudes towards pricing models for certain mobility services. First, the participants were asked whether they would prefer a dynamic price for a flight, which varies between 50 and 150 euros, rather than a static price of 100 euros. With 46.98 percent to 39.53 percent, the respondents tended to prefer dynamic prices.

When asked whether consumers would prefer dynamic or static prices for a car offered via car sharing, 59.07 percent preferred the static price of $0.30 € / \mathrm{min}$. Only 29.77 percent were in favour of the dynamic model, which fluctuates in an interval of $0.20-0.40 € / \mathrm{min}$. No significant differences could be identified with regard to demographic characteristics.

Also in the mobility-specific question regarding the transparency of prices, costs and pricing criteria, a result similar to that in the dynamic pricing section, as well as in the trade-specific section, was found.

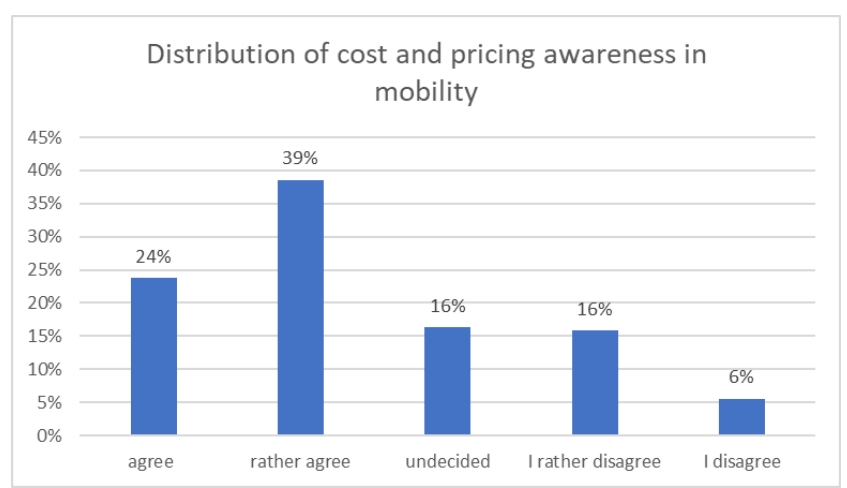

Figure 2. Distribution of cost and pricing awareness in mobility

According to the data, 53 percent of all participants see the airline industry as an advantageous sector for the application of dynamic pricing models; in the remaining sectors, as can be seen below, there is a variation between 25 and 33 percent.

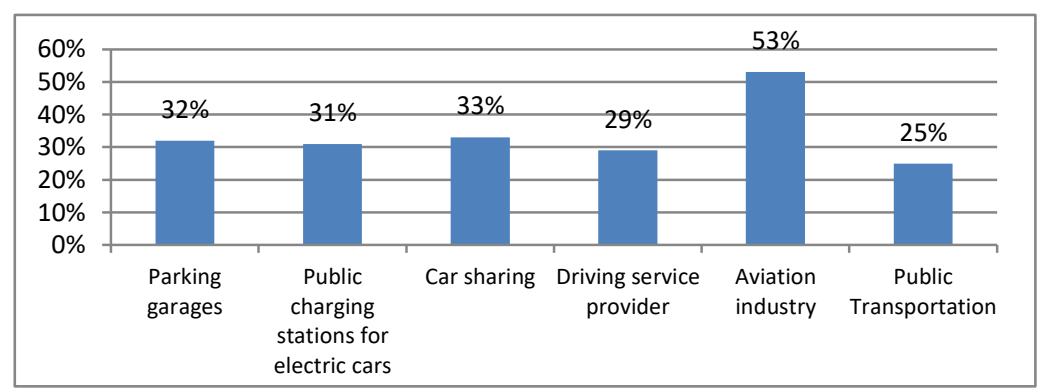

Figure 3. Advantages of dynamic pricing models 


\subsection{Energy Supply}

The following distribution shows the willingness of the test persons to reduce their electricity costs with the help of smart devices. $73.48 \%$ are rather or very likely to minimize their costs with the help of programmable devices.

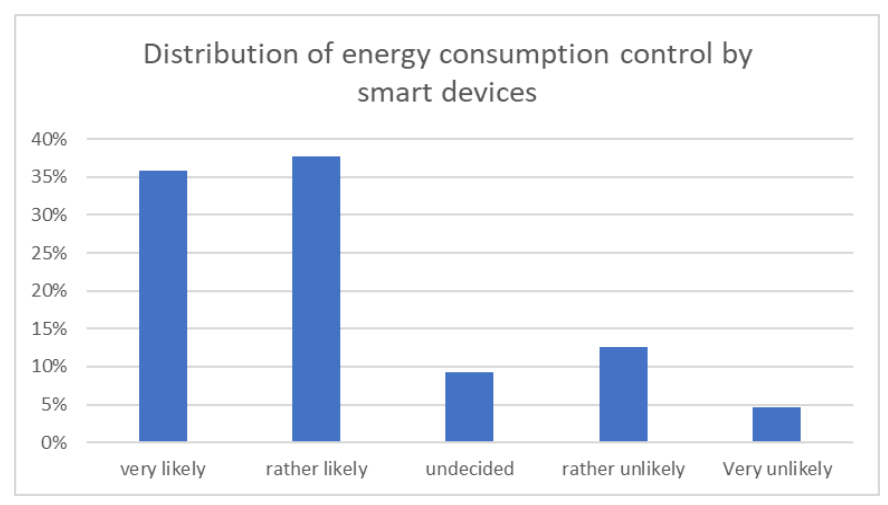

Figure 4. Distribution of energy consumption control by smart devices

The cross-tabulation shows that especially the up to 27-year-olds (age group 1) are very likely to use the new technologies for cost minimization. The highest level of scepticism occurs among the over 50s (age group 3), of this group 31.6 percent stated that it is rather unlikely that they will use smart devices to reduce electricity costs.

Table 5. Cross-tabulation of energy consumption control by smart devices

\begin{tabular}{|c|c|c|c|c|c|c|c|}
\hline & & Rather unlikely & Rather likely & Very unlikely & Very likely & Undecided & total \\
\hline \multirow[t]{6}{*}{ age groupings } & 1 Quantity & 7 & 55 & 5 & 55 & 13 & 135 \\
\hline & $\%$ within age groupings & $5.2 \%$ & $40.7 \%$ & $3.7 \%$ & $40.7 \%$ & $9.6 \%$ & $100.0 \%$ \\
\hline & 2 Quantity & 14 & 19 & 5 & 17 & 6 & 61 \\
\hline & $\%$ within age groupings & $23.0 \%$ & $31.1 \%$ & $8.2 \%$ & $27.9 \%$ & $9.8 \%$ & $100.0 \%$ \\
\hline & 3 Quantity & 6 & 7 & 0 & 5 & 1 & 19 \\
\hline & $\%$ within age groupings & $31.6 \%$ & $36.8 \%$ & $0.0 \%$ & $26.3 \%$ & $5.3 \%$ & $100.0 \%$ \\
\hline \multirow[t]{2}{*}{ total } & Quantity & 27 & 81 & 10 & 77 & 20 & 215 \\
\hline & $\%$ within age groupings & $12.6 \%$ & $37.7 \%$ & $4.7 \%$ & $35.8 \%$ & $9.3 \%$ & $100.0 \%$ \\
\hline
\end{tabular}

In order to test consumers' perception of costs, this survey asked them to switch electricity providers frequently in order to see how sensitive they are to electricity costs and how valuable the commodity of electricity is perceived to be. The distribution indicates that more than half of the total participants and respondents have not switched electricity providers in the last five years. Only 2.79 percent indicate that they have switched suppliers more than three times. The distribution on the energy market risk shows that the participants are very indifferent to the strong fluctuations of the market. Only 5.58 percent indicate an affinity for risk, in contrast, 9.30 percent do not want to expose themselves to market risk under any circumstances. These are the research results from the quantitative research, which are subsequently analysed and used to answer research question two.

\section{Presentation of Results of Quantitative Research}

The table below provides a quick overview of the results of the hypothesis testing, and the subsequent chapters provide detailed justifications for the tests. There are several common techniques for hypothesis testing. In the current study, the results are quite straightforward, so no particular correlation tests needed to be done. 
Table 6. Hypothesis testing

\begin{tabular}{llll}
\hline Hypothesis testing & & & \\
\hline Dynamic & H1 & & confirmed \\
Pricing & H2 & & Confirmed \\
& H3 & & Confirmed \\
Trade & H4 & & Rejected \\
& H5 & & Confirmed \\
& H6 & & Confirmed \\
& H7 & a) & Confirmed \\
& H8 & b) & Rejected \\
& & & Confirmed \\
Mobility & & a) & Rejected \\
& & b) & Rejected \\
& H9 & c) & Rejected \\
& & d) & Rejected \\
& & e) & Confirmed \\
& & f) & Rejected \\
Energy supply & H10 & & Confirmed \\
& H11 & & Confirmed \\
& & & Confirmed \\
\hline
\end{tabular}

\subsection{Dynamic Pricing}

With the help of the analyzed results from the online survey, the hypotheses on the Dynamic Pricing section are now tested.

H1: Dynamic pricing models give consumers the perception of being able to purchase products at lower prices.

Regarding the hypothesis, the survey revealed that the vast majority compares prices online before making a purchase decision and can buy products at lower prices by deliberately waiting. This means that hypothesis 1 can be confirmed. An extremely clear result was found among those under 50 years of age.

H2: Consumers perceive the inclusion of personal data in the pricing process as unfair.

For hypothesis 2, two questions were integrated into the questionnaire to test whether consumers perceive the inclusion of personal data as fair if they are granted a monetary advantage or disadvantage. The result of the survey reflected the hypothesis that even in the case of a personal advantage, the price difference is not perceived as justified or unfair. It can therefore be stated that hypothesis 2 was confirmed.

\section{H3: Transparency of prices in terms of costs and pricing criteria is very important to consumers.}

The hypothesis regarding the transparency of costs and pricing criteria could be confirmed by the analysis of the data material, the vast majority of respondents indicated that this information is of high interest to them.

\subsection{Trade}

Now the hypotheses are tested with reference to trade on the basis of the results.

H4: Electronic price labels in stationary retail trade worry consumers with regard to momentary price changes.

From the expert interviews it could be deduced that consumers may be concerned by electronic shelf labelling. No clear result emerged from the survey in this case. Just under 43 percent stated that the possibility of real-time price changes worries them, 38 percent stated that they are not worried at all, and the rest are indifferent. This hypothesis cannot therefore be clearly confirmed.

H5: Steering effects through dynamic price models show effect in stationary food retailing. Consumers satisfy their demand during periods of lower prices.

Two questions were used to test this hypothesis. The first is aimed at the price sensitivity of consumers and was carried out using a thought experiment. This experiment is intended to show at what price differences consumers are willing to change their usual shopping behavior. It was found that ten percent of the participants were already prepared to make their purchases at a different time from a price change of ten percent. It should be noted that especially age group 1, i.e. all persons younger than 27 years, show the greatest willingness to change their 
shopping behaviour.

Following this thought experiment, the participants were asked the direct question of whether they would be prepared to change their shopping behaviour on the basis of monetary benefits. The result shows a clear agreement with 77.68 percent, which means that hypothesis 5 is confirmed.

H6: Consumers would like to see greater transparency of prices with regard to costs and pricing criteria in e-commerce.

The hypothesis relating to online retailing, with its focus on the transparency of costs and pricing criteria, could be confirmed, showing a similar level of agreement as in the Dynamic Pricing section.

\subsection{Mobility}

This subchapter deals with the testing of hypotheses related to mobility.

H7: Consumers prefer dynamic pricing models a) in the airline industry and b) in car sharing.

In hypothesis 7, the approval of the already established dynamic pricing model in the airline industry was questioned in order to obtain a comparative value for the mobility service "car sharing". Approval of dynamic pricing was recorded at just under 47 percent, as almost 14 percent of the participants were indifferent in this respect. However, in car sharing, rejection of dynamic pricing was found. 59.07 percent voted for static prices, only 29.77 percent for dynamic prices, the rest were undecided. Hypothesis 7 a) can therefore be confirmed, whereas hypothesis $7 \mathrm{~b}$ ) must be rejected.

H8: Consumers would like to see greater transparency of prices with regard to costs and pricing criteria in the mobility sector.

The hypothesis on the transparency of costs and pricing criteria was also confirmed in relation to the mobility sector with a similar distribution as in the other sections.

H9: Consumers can benefit from dynamic pricing models in the case of
a) Parking garages
b) Public charging points for electric cars
c) Car sharing
d) Driving service provider
e) Aviation industry
f) Public transport

recognize personal price advantages.

The test of this hypothesis is to show in which transportation concepts the participants and the participants perceive dynamic pricing strategy as beneficial. The result shows that 53 percent of the participants perceive dynamic pricing as beneficial in the airline industry. In the remaining mobility sectors, dynamic pricing models were identified as not beneficial by the vast majority.

\subsection{Energy Supply}

Finally, the hypotheses are tested with reference to energy supply.

H10: Consumers would be willing to adapt their energy consumption to real-time market changes with the help of smart devices in order to reduce energy costs.

Hypothesis ten is intended to show that with the help of technological advances through smart devices, consumers are willing to adjust their energy consumption through monetary incentives. This hypothesis was confirmed with an overwhelming agreement of 73.48 percent, with age group 1, the up to 27 -year-olds, showing a particularly pronounced agreement.

\section{H11: Consumer demand for energy is very inelastic, as electricity is perceived as a commodity.}

In order to find out how high the price sensitivity of consumers is with regard to the product electricity, the participants were asked how often they had changed their electricity supplier or tariff in the last five years. From this it can be concluded how high the impact is on the household budget of the respondents and whether electricity is perceived as a commodity by the society as revealed from the expert interview. 54.42 percent of the respondents stated that they have not switched in the last 5 years, thus hypothesis eleven can be confirmed.

H12: Consumers do not want to be at the mercy of the market risk of the energy wholesale market. 
Hypothesis twelve is to confirm that the participants are rather risk averse and do not want to expose themselves to the wholesale energy market fluctuations. 42.02 percent of the respondents are not willing to expose themselves to this risk, almost one third are undecided, the rest would accept the fluctuations for any advantages. Since the majority of respondents consider the benefits to be too small compared to the risk, hypothesis twelve can be confirmed.

\section{Conclusion}

Based on the analysed data material from the qualitative research, the following question will now be answered.

What opportunities and challenges are developing with regard to dynamic pricing strategies in retail, mobility services and energy supply?

Regarding question one, which refers to the opportunities and challenges of dynamic pricing, it can be stated that above all the market situation and the cost and price awareness of consumers play an important role in the application of dynamic pricing. For products in highly competitive markets, the inclusion of personal as well as environmental real-time information offers new opportunities to maximize profit. It should be noted, however, that for the application of dynamic pricing, a high level of involvement in the product must be present. For convenience products, i.e. goods for daily use, dynamic prices are perceived as disadvantageous by consumers. Especially in online sales processing, new technologies make it possible to estimate consumers' reservation prices more and more precisely. Due to the rapid price changes, it is becoming increasingly difficult for authorities to identify price agreements or cartels, which can lead to unfair competition. The European Union's General Data Protection Regulation must also be observed with regard to personal data processing, which means that the personalisation of prices is not permitted without the explicit consent of customers. Due to the increasing integration of digital media into everyday life and the resulting digital footprints, it can be assumed according to the results of qualitative research that personalised prices will be increasingly used for online purchases.

In stationary retail, personalized dynamic prices are not possible due to the price display by signs, but the electronic price signs are new, which allow price changes in real time. These are mainly used in the new branches of the retailers. By using these, not only can personnel costs be saved for the display of products, but they can also be used for dynamic pricing models. Despite the given possibility, it is questionable whether dynamic prices with time-based criteria will be introduced by companies, as a loss of consumer confidence can have fatal consequences in this highly competitive market. Online retailing already uses dynamic pricing models in many cases. However, it is difficult to establish dynamic pricing models in the online grocery trade, as consumers expect to receive the same prices on all distribution channels.

In Germany, the first large car park operators have already integrated dynamic pricing models to optimise capacity utilisation. For steering effects from private passenger transport to public transport, a dynamic pricing model will not be sufficient to achieve decisive effects. For consumers, the price reduction is too small to achieve a switch in mobility. Furthermore, dynamic pricing in public transport can lead to a lower demand, as consumers do not know which price they will have to pay.

Public charging points for electric vehicles will not follow dynamic pricing models in the future. For energy providers and grid operators, it is more lucrative to offer a full charge within a certain period of time, as they can control charging activities depending on the grid load. Smart meters also pose new challenges for energy providers. If grid operators were to change their charging system to a more flexible dynamic pricing model, this would present new opportunities for lucrative business models in cooperation with energy providers. From a technical perspective, there is also potential for optimisation with smart meters; although these can measure energy consumption in short cycles, the data is not made available until the following day, which poses challenges for real-time pricing models. The trend towards higher electricity consumption through heat pumps and e-mobility - but also self-generation through photovoltaic systems - will lead to a new perception and associated cost awareness for electricity as a commodity. This makes it possible to establish new dynamic price models, as customers show a higher level of involvement in electricity as a product.

To answer the second question, hypotheses were derived from the data material of the qualitative survey. In order to test these hypotheses, a quantitative survey was subsequently conducted by means of an online survey. The results of the hypothesis testing will now contribute to answering the second research question.

Can consumers consider dynamic personal prices to be an advantage in the retail, mobility or energy supply sectors?

The results show that consumers feel that dynamic prices satisfy their demand more cheaply. However, it should be noted that price fluctuations must be within a range that is comprehensible to the consumer. If there is a lack 
of transparency with regard to costs and pricing criteria, consumers will feel a strong sense of injustice. Information symmetry is important in order to bind customers to a company in the long term. If consumers notice any incomprehensible price differences, this leads to punitive reactions and a strain on the relationship between the customer and the company.

For the stationary trade, no clearly negative attitude towards electronic price tags could be determined. For differentiated prices for certain foodstuffs (favoured lunch), an approval on the part of the consumers could be ascertained. This shows that consumers are open to adjusting their shopping behaviour by means of dynamic prices. For companies, this results in cost optimisation potentials. However, it is also true for retailers that consumers need a certain degree of transparency in order not to lose trust in the company. This transparency could be ensured by labelling the price fluctuation intervals. If consumers feel that they are being treated unfairly by withholding information, this can also lead to negative and damaging reactions for companies in the retail sector.

In terms of mobility, dynamic pricing has already proven itself in the aviation industry and is well accepted. This could not be confirmed for car sharing models. Out of six possible mobility services, only aviation was found to be advantageous by the test persons. This can possibly be attributed to the lack of transparency with regard to the costs of the transport service, or also to the reason that short-haul mobility is regarded as a convenience good and consumers therefore tend to prefer static prices. Flight bookings are made for holiday purposes for the majority of society, which is why these are increasingly seen as special products for which dynamic pricing models are perceived as positive. Electricity is also perceived as an everyday consumer good, but new technologies such as smart appliances would make consumers more willing to shift energy-intensive uses to times when prices are lower. However, if such products are not available in households, electricity consumption is too low a source of savings, which means that consumers would not be willing to expose themselves to large-scale energy market risk. In conclusion, it can be said that consumers perceive dynamic pricing as positive, especially in the case of special products and luxury goods, provided that the pricing criteria are transparent, and that they expect a personal advantage as a result.

\section{References}

Bonacchi, M., \& Perego, P. (2019). Customer Accounting: Creating Value with Customer Analytics. Cham: Springer International Publishing Imprint: Springer. https://doi.org/10.1007/978-3-030-01971-6

Goensch, J., Klein, R., \& Steinhardt, C. (2009). Dynamic pricing-state-of-the-art. Journal of Business Economics, Supplement, 3, 1-40. http://ssrn.com/abstract $=2179225$

Guan-Ru, C., \& Miao-Ling, C. (2011). The Link between Purchase Delay and Resale Price Maintenance: Using the Real Options Approach. International Journal of Economics and Finance, 3(1). https://doi.org/10.5539/ijef.v3n1p171

Hannak A. et al. (2014). Measuring Price Discrimination and Steering on E-commerce Web Sites (pp. 305-318). https://doi.org/10.1145/2663716.2663744

Hartmann, M. (2006). Preismanagement im Einzelhandel. Wiesbaden: Deutscher Universität-Verlag / GWV Fachverlage.

Heinemann, G., Gehrckens, H. M., \& Täuber, T. (2019). Trading with added value - Digital transformation in markets, business models and business systems. Wiesbaden: Springer Fachmedien Wiesbaden.

Helmedag, F. (2001). Price differentiation. WiSt - Wirtschaftswissenschaftliches Studium, 30, 10-16. https://doi.org/10.15358/0340-1650-2001-1-10

Horvath, L. (2019). Algorithms and Prices - The Individualization of Prices in the Online-Commerce. Retrieved from https://www.netidee.at/sites/default/files/2019-12/pr3523_call13_Studienbericht_Final.pdf

Olbrich, R., \& Battenfeld, D. (2014). Pricing Policy: An Introductory Textbook and Exercise Book (2nd ed.). 2014 ed., Berlin, Heidelberg: Springer Berlin Heidelberg, 2014.

Oxera. (2018). When algorithms set prices: winners and losers. Retrieved from https://www.oxera.com/wp-content/uploads/2018/07/When-algorithms-set-prices-winners-and-losers.pdf.pd $\mathrm{f}$

Schuppar, B. R., Schuppar, B., \& Homburg, P. D. C. (2006). Preismanagement. Germany: Springer Verlag.

Simon, H., \& Fassnacht, M. (2019). Price Management: Strategy, Analysis, Decision, Implementation. Cham: Springer International Publishing Imprint: Springer, 2019. https://doi.org/10.1007/978-3-319-99456-7 
Spann, M., Fischer, M., \& Tellis, G. J. (2015). Skimming or penetration? Strategic dynamic() pricing for new products. Marketing Science, 34(2), 235-249. https://doi.org/10.1287/mksc.2014.0891.

Taillard, M.. \& Trochet-Macé, E. (2014). IP Tracking: conclusions de l'enquête conjointe menée par la CNIL and la DGCCRF. Retrieved from https://www.economie.gouv.fr/files/files/directions_services/dgccrf/presse/communique/2014/cp_tracking _ 27012014.pdf

Vetter, P. (2019). If you have an iPhone or shop at Chanel, you pay more at Sixt. World, 2019.

\section{Copyrights}

Copyright for this article is retained by the author(s), with first publication rights granted to the journal.

This is an open-access article distributed under the terms and conditions of the Creative Commons Attribution license (http://creativecommons.org/licenses/by/4.0/). 